\title{
(2) \\ What We Know About AWOL and Desertion: A Review of the Professional Literature for Policy Makers and Commanders
}

\author{
ARI Special Report 51, August 2002 \\ Peter F. Ramsberger \\ Human Resources Research Organization \\ D. Bruce Bell \\ U.S. Army Research Institute
}
U.S. Army Research Institute for the Behavioral and Social Sciences 5001 Eisenhower Avenue • Alexandria, VA 22333-5600 Internet site: http://www.ari.army.mil

